\title{
ANALISIS PROSPEKTIF KEBIJAKAN PENGHAPUSAN PEMBELAJARAN CALISTUNG PADA KELAS RENDAH SEKOLAH DASAR
}

\author{
Maulana Amirul Adha; Asep Sunandar; Nova Syafira Ariyanti \\ Manajemen Pendidikan Pascasarjana Universitas Negeri Malang \\ Jalan Semarang No.5 Malang Jawa Timur Indonesia \\ amirulmaulana1013@gmail.com
}

\begin{abstract}
The purpose of this study was to describe the prospect policy, forecast future policy, and compile policy recommendations of the elimination of "calistung" learning policies in the lower classes of elementary schools in Malang city. The method used in this study is descriptive qualitative. This study analyzed using the public policy prospective analysis theory from Dunn. This research in collecting data using interview techniques, and study reference. The key informant is the principal and additional informants namely the teacher and parents of students. The findings of the study are (1) The core of the substantive problem of policy is the problem of skills student and school curriculum; (2) The results of policy forecasting show the competitiveness of students towards "calistung" is slow; and (3) Policy recommendations made by the education authorities should immediately formulate policy guidelines, and schools can get around the "calistung" program by inserting on character building or educational games.
\end{abstract}

Keyword: prospective analysis; public policy; "calistung”; elementary school

\begin{abstract}
Abstrak: Tujuan dari penelitian ini adalah untuk mendeskripsikan prospek kebijakan, meramalkan masa depan kebijakan, dan menyusun rekomendasi kebijakan penghapusan pembelajaran calistung pada kelas rendah sekolah dasar di kota Malang. Metode yang digunakan dalam penelitian ini adalah kualitatif deskriptif. Penelitian ini melakukan analisis menggunakan teori analisis prospektif kebijakan publik dari Dunn. Penelitian ini dalam pengumpulan data menggunakan teknik wawancara, dan kajian kepustakaan. Key Informan yakni kepala sekolah dan informan tambahan yakni guru dan orang tua siswa. Temuan dari penelitian yakni (1) Inti permasalahan substantif kebijakan yaitu masalah kecakapan dan kurikulum sekolah; (2) Hasil peramalan kebijakan menunjukkan daya cakap siswa terhadap calistung lambat; dan (3) Rekomendasi kebijakan dilakukan dinas pendidikan seyogyanya segera menyusun panduan kebijakan, serta sekolah dapat menyiasati program calistung dengan menyisipkan pada pembinaan karakter atau permainan edukasi.
\end{abstract}

Kata kunci: analisis prospektif; kebijakan publik; calistung; pendidikan dasar

Penelitian ini bertujuan untuk mendeskripsikan prospek kebijakan, melakukan peramalan masa depan kebijakan, dan menyusun rekomendasi kebijakan penghapusan calistung (baca, tulis, hitung) pada kelas rendah (kelas 1 dan 2), Sekolah Dasar di Kota Malang dengan menggunakan analisis prospektif. Analisis prospektif adalah produksi serta transformasi informasi sebelum aksi kebijakan dimulai dan di implemetasikan (Dunn, 2000). Pada dasarnya, analisis dapat dilakukan di setiap langkah kebijakan publik. Pada penelitian ini, analisis dilakukan pada tahapan pra implementasi kebijakan publik. Penghapusan pembelajaran calistung pada kelas rendah sekolah dasar bertujuan untuk memberikan penguatan pada pendidikan karakter pada siswa SD di kota Malang. Dikutip dari Malangtimes.com (2019) kepala dinas pendidikan kota malang menyatakan penghapusan calistung diberlakukan bagi siswa SD kelas 1 dan 2, sebagai gantinya penguatan pendidikan karakter lebih ditingkatkan. 
Kebijakan yang akan digulirkan oleh pemerintah kota Malang terus menuai pro kontra, oleh karenanya kebijakan penghapusan pembelajaran calistung pada kelas rendah sekolah dasar di kota Malang ini menarik dikaji untuk menemukan dan mendeskripsikan prospek kebijakan yang akan di implementasikan. Berdasarkan jabaran masalah diatas peneliti dapat merumuskan masalah penelitian yakni bagaimanakah prospek kebijakan penghapusan. Pendekatan ilmu kebijakan biasanya didasarkan pada efisiensi (Adams, 2015). Kebijakan merupakan serangkaian keputusan atau tindakan-tindakan sebagai akibat dari interaksi terstruktur dan berulang diantara berbagai aktor, baik pemerintah maupun swasta yang terlibat berbagai cara dalam merespon, mengidentifikasi, dan memecahkan suatu masalah yang secara politis didefinisikan sebagai masalah publik (Knoepfel, 2007; Lundy, 2012). Arah tindakan yang dilakukan pemerintah dapat diartikan sebagai kebijakan publik. Kebijakan publik meliputi segala tindakan yang dilakukan oleh pemerintah dan mempunyai pengaruh besar terhadap masyarakat. Menurut Dunn (2000) Analisis kebijakan yaitu aktivitas intelektual dan praktis yang ditujukan untuk menciptakan, menilai, dan mengkomunikasikan pengetahuan tentang dan dalam proses kebijkan.

Berdasarkan pendapat ahli diatas dapat disimpulkan analisis kebijakan merupakan aktivitas intelektual yang menjabarkan fenomena dari suatu kebijakan serta sebab akibat yang mengikutinya. Analisis kebijakan sangat berguna untuk merumuskan ataupun mengimplementasikan kebijakan publik. Menurut Widodo dalam Damayanti (2017) analisis kebijakan dapat dilakukan pada setiap policy process yaitu pada tahapan formulasi, implementasi ataupun pada tahap evaluasi kebijakan. Hasil dari analisis kebijakan diharapkan mampu memberikan informasi yang relevan dan siap disuguhkan kepada pembuat keputusan atau kebijakan. Model analisis kebijakan publik adalah seperangkat alat bantu konseptual yang berguna sebagai pembimbing langkah bagi para analis kebijakan. Secara umum model analisis kebijakan menurut Stokey (2009) terdiri atas, (1) model matematika formal, yakni model yang menggambarkan secara eksplisit tentang perubahan kuantitatif dalam variabel tertentu atau sistem dalam menanggapi berbagai rangsangan; (2) model deskriptif dan preskriptif, model deskriptif merupakan model yang menunjukkan secara lebih jelas mengenai apa yang diperlukan dan apa hasil dari suatu tindakan yang dilakukan. Model preskriptif yakni model yang memberikan aturan untuk membuat pilihan optimal, model ini membantu membuat suatu tindakan program; dan (3) model deterministik dan probabilistik, model deterministik menggunakan nilai rata-rata yang dianggap baik. Model probabilitas yakni sebuah model yang mempertimbangkan berbagai kemungkinan hasil dimana probabilitas dapat diperkirakan. Pada penelitian ini, peneliti menggunakan model deskriptif.

Bentuk-bentuk analisis kebijakan publik menurut Dunn (2000) ada tiga. Pertama, analisis prospektif adalah produksi serta transformasi informasi sebelum aksi kebijakan dimulai dan di implemetasikan. Analisis kebijakan yang dimaksud merupakan suatu alat untuk mensintesakan informasi untuk dipakai dalam merumuskan alternatif dan preferensi kebijakan yang dinyatakan secara komparatif, diramalkan dalam bahasa kuantitatif dan kualitatif sebagai landasan atau penuntun dalam pengambilan keputusan kebijakan. Kedua, analisis retrospektif, yakni penciptaan atau transformasi informasi sesudah aksi kebijakan dilakukan. Ketiga, analisis terintegrasi yakni gabungan antara analisis prospektif dan retrospektif. Analisis ini cenderung kepada penciptaan transformasi kebijakan sebelum dan sesudah aksi kebijakan dilaksanakan. Analisis terintegrasi adalah penyempurna dari kedua analisis sebelumnya. Analisis Prospektif Kebijakan Publik menurut Dunn (2000) terdapat tiga langkah,dijelaskan sebagai berikut, Langkah pertama yakni perumusan masalah, yakni kegiatan yang dapat membantu menemukan asumsi-asumsi tersembunyi, menganalisis penyebabnya, dan menjabarkan tujuan-tujuan yang memungkinkan serta merancang peluang-peluang kebijakan yang baru. Perumusan masalah dianggap sebagai kegiatan yang paling penting dari para analis kebijakan dikarenakan menelaah berbagai formulasi masalah yang saling berbeda dari para pelaku kebijakan. Perumusan kebijakan terdiri atas beberapa tahapan yakni pencarian masalah (problem search), pendefinisian masalah (problem definition), spesifikasi masalah (problem spesification), dan pengenalan masalah (problem sensing).

Langkah kedua yakni peramalan kebijakan, yaitu salah satu ranah dalam analisis prospektif suatu kebijakan. Peramalan masa depan kebijakan sangat penting guna perbaikan pembuatan suatu kebijakan itu sendiri. Melalui peramalan, analis dapat memperoleh visi yang prospektif. Peramalan digunakan untuk memperoleh informasi mengenai perubahan di masa depan yang akan mempengaruhi implementasi 
kebijakan dan konsekuensinya. Langkah ketiga yaitu rekomendasi kebijakan, yakni informasi yang memungkinkan seorang analis tentang kemungkinan di masa depan untuk menghasilkan konsekuensi yang berharga bagi individu, kelompok atau masyarakat seluruhnya. Rekomendasi memiliki prosedur yakni meliputi transformasi mengenai aksi-aksi kebijakan yang akan menghasilkan keluaran yang bernilai. Untuk merekomendasikan suatu tindakan kebijakan khusus diperlukan adanya informasi tentang konsekuensi-konsekuensi di masa depan setelah dilakukannya berbagai alternatif tindakan.

Pembelajaran calistung meliputi membaca, menulis dan berhitung. Menurut Anderson dalam Saniy (2014) membaca merupakan suatu proses untuk memahami makna dari suatu tulisan. Proses tersebut meliputi penyajian kembali dan penafsiran suatu tulisan yang dimulai dengan pengenalan huruf, kata, ungkapan, frase, kalimat dan wacana serta menghubungkannya dengan bunyi dan maknanya . Menulis adalah kegiatan yang membutuhkan ketelatenan, kerapian, dan konsistensi. Dengan berlatih menulis, terutama susunan huruf dan kata, baik besar, kecil, maupun tegak bersambung, maka sifat ketelatenan, kerapian, dan konsistensi akan terserap dalam karakter anak. Artinya, menulis bukan hanya suatu keterampilan yang harus dikuasai oleh setiap anak agar mampu membaca dan menulis dengan baik. Itulah sebab muncul grafologi, yaitu ilmu membaca karakter seseorang melalui tulisan. Kegiatan berhitung pada siswa kelas rendah sekolah dasar disebut juga sebagai kegiatan menyebutkan urutan bilangan atau membilang buta.

\section{METODE}

Metode yang digunakan dalam penelitian ini adalah kualitatif deskriptif. Penelitian kualitatif merupakan metode-metode untuk mengeksplorasi dan memahami makna yang oleh sejumlah individu atau sekelompok orang berasal dari masalah sosial atau kemanusiaan (Creswell, 2014). Menurut Ulfatin (2015) penelitian kualitatif deskriptif bertujuan untuk menggambarkan karakteristik fenomena dengan penjabaran yang bersifat naratif. Penelitian ini dalam melakukan analisis prospektif kebijakan penghapusan calistung kelas rendah Sekolah Dasar di Kota Malang menggunakan teori analisis prospektif kebijakan publik dari Dunn (2000). Penelitian ini dalam pengumpulan data menggunakan teknik wawancara, dan kajian kepustakaan. Key Informan dalam penelitian ini yakni kepala sekolah dan informan tambahan yakni guru dan orang tua siswa. Kajian kepustakaan dalam penelitian ini menggunakan berbagai sumber yakni surat kabar, internet, jurnal, dan buku yang relevan dengan masalah yang dikaji. Pengecekan keabsahan data digunakan peneliti untuk mempertanggungjawabkan data yang telah diperoleh. Pengecekan keabsahan data dilakukan kredibilitas, karena dengan kredibilitas (credibility) sudah mencukupi untuk dilakukan pengecekan keabsahan data. Kredibilitas tersebut meliputi triangulasi, meningkatkan ketekunan, serta kecukupan referensi.

\section{HASIL DAN PEMBAHASAN}

\section{Analisis Prospektif Kebijakan Penghapusan Calistung Kelas Rendah Sekolah Dasar}

Berdasarkan hasil wawancara dan studi kepustakaan, kebijakan penghapusan pembelajaran calistung pada kelas rendah sekolah dasar di Kota Malang terus menuai pro dan kontra salah satunya dari SD Sabilillah Kota Malang. Hal ini dikarenakan SD Sabilillah memiliki program yang berkaitan dengan calistung, yakni program 4R (writing, reading, arithmetics, dan reasoning). Program tersebut nantinya menghasilkan luaran 4C yakni critical thinking, creativity, collaboration, dan communication. Apabila kebijakan penghapusan pembelajaran tetap dihapuskan program 4R juga akan terdampak.

Timbulnya kekhawatiran baik dari sekolah maupun orang tua siswa mengenai kecakapan siswa terhadap calistung cenderung lambat, jika kebijakan ini digulirkan. Kekhawatiran tersebut bukan tanpa sebab, orangtua siswa masih memiliki pandangan bahwa kecakapan anak terhadap calistung sangat penting, pada saat anak memasuki jenjang pendidikan pra sekolah anak-anak mereka tidak dibelajarkan mengenai calistung, ketika anak tidak diusia sekolah kelas rendah tidak dibelajarkan calistung timbul kekhawaitiran tersebut. Untuk mengetahui masa depan kebijakan penghapusan pembelajaran calistung tersebut, dapat diketahui melalui analisis kebijakan prospektif. 
Analisis prospektif menurut Dunn (2000) ialah seputar tentang apa saja yang akan terjadi apabila suatu kebijakan tersebut diimplementasikan termasuk konsekuensi-konsekuensi apa yang akan terjadi serta apa yang harus dilakukan untuk meminimalisir hal-hal yang tidak diinginkan apabila terjadi di masa yang akan datang. Lebih lanjut Dunn (2000) menyatakan bahwa analisis prospektif meliputi tahapan merumuskan masalah kebijakan, mencoba meramal masa depan kebijakan terkait penelitian yakni "Analisis Prospektif Kebijakan Penghapusan Calistung pada Kelas Rendah di Kota Malang" kemudian didapatkan rekomendasi sebagai langkah untuk melakukan suatu aksi kebijakan yang tepat.

Perumusan masalah kebijakan dilakukan peneliti menggunakan metode in-depth analysis. Inti dari merumuskan masalah kebijakan adalah didapatinya permasalahan substantif yaitu masalah kecakapan dan kurikulum sekolah. Alasan utama orang tua siswa dan sekolah kontra dengan adanya kebijakan ini adalah kekhawatiran kecakapan siswa terhadap calistung cenderung lambat, jika kebijakan ini digulirkan serta sekolah yang sebelumnya merumuskan kurikulum dan program yang erat kaitannya dengan pembelajaran calistung pasti akan terganggu.

Analisis prospek masa depan kebijakan penghapusan pembelajaran calistung pada kelas rendah di kota Malang, peneliti menerapkan bentuk peramalan prediksi yaitu ramalan yang didasarkan pada asumsi teoritik. Asumsi ini dapat berbentuk hukum teoritis, proposisi teoritis, atau analogi. Hasil peramalan kebijakan menunjukkan daya cakap siswa terhadap calistung lambat. Hal ini dikarenakan anak dianggap matang secara motorik dan sensorik mulai usia 6 atau 7 tahun (pada usia SD kelas rendah), pada usia inilah yang tepat untuk membelajarkan anak-anak calistung dengan catatan anak sudah benar-benar siap untuk belajar. Penguatan pendidikan karakter di sekolah dapat dilakukan dengan tidak mengorbankan anak untuk terlambat belajar calistung. Pembelajaran calistung merupakan pembelajaran dasar bagi anak usia sekolah untuk memperluas pengetahuan terlebih lagi menumbuhkan budaya literasi dan minat baca siswa sejak dini.

\section{Rekomendasi Pemecahan Masalah Kebijakan Penghapusan Calistung Kelas Rendah Sekolah Dasar}

Berdasarkan perumusan masalah dan peramalan kebijakan penghapusan pembelajaran calistung pada kelas rendah sekolah dasar di kota Malang, peneliti menetapkan analisis untuk rekomendasi kebijakan yaitu pemerintah kota dalam hal ini dinas pendidikan kota malang seyogyanya segera menyusun panduan kebijakan sebagai pedoman pelaksanaan kebijakan bagi sekolah. Panduan kebijakan yang dibuat oleh pemerintah penting disusun agar sekolah dapat melaksanakan kebijakan dengan baik dan sesuai koridor yang telah ditetapkan. Bagi sekolah pada penerapannya dapat menyiasati program atau pembelajaran calistung dengan menyisipkan pada pembinaan karakter atau dalam permainan edukasi.

Setelah tahap pendidikan anak usia dini atau pra sekolah, anak-anak mulai memasuki jenjang sekolah dasar antara usia 6 hingga 7 tahun dan ketika mereka memasuki lingkungan sekolah, mereka mengambil tanggung jawab baru di samping tanggung jawab yang mereka miliki di rumah mereka. Selama periode ini, anak-anak menghadapi tantangan tanggung jawab baru termasuk mematuhi peraturan sekolah, bergaul dengan teman-teman mereka, menjalin hubungan dengan orang dewasa lain selain orang tua mereka, dan mengatur waktu mereka (Guven, Ozturk \& Duman; 2016). Pada tahun pertama, anak-anak diharapkan menyesuaikan diri dengan perubahan ini dan mulai tahun kedua dan seterusnya, mereka diharapkan menyadari tanggung jawab baru mereka. Artinya penguatan pendidikan karakter pada masa awal anak masuk sekolah sangatlah penting, maka tidak salah jika pemerintah menghendaki fokus masa awal siswa bersekolah pada jenjang pendidikan dasar adalah penguatan pendidikan karakter.

Penguatan pendidikan karakter di Indonesia dirumuskan terdapat lima nilai utama yakni nasionalis, integritas, mandiri, gotong royongm dan religius. Sedangkan Guven, Ozturk dan Duman (2016) merumuskan dua belas nilai atau karakter universal yang penting diajarkan pada siswa, yaitu kerja sama, kemandirian, kebahagiaan, kejujuran, cinta, kesederhanaan, kedamaian, rasa hormat, tanggung jawab, kesederhanaan, toleransi dan persatuan. Karakter-karakter yang disebutkan sebelumnya penting dimiliki oleh siswa, maka perlu dirumuskannya panduan bagi sekolah untuk merumuskan kegiatan pendidikan maupun pembelajaran yang mendukung proses penguatan pendidikan karakter di sekolah. 
Karakteristik umum dalam kebijakan pengembangan dan strategi reformasi pendidikan global saat ini adalah meningkatkan fokus pada melek huruf (literasi) dan berhitung (Sahlberg, 2007). Pengetahuan dan keterampilan dasar siswa dalam membaca, menulis, matematika, dan ilmu alam telah ditingkatkan untuk menjadi target utama dan indeks reformasi pendidikan global saat ini, maka penting bagi sekolah dalam mengajarkan siswa nya mengenai membaca, menulis dan berhitung sejak masa awal memasuki sekolah. Hal ini didukung oleh pendapat (Cullinan, 2000) yang menyatakan "children should be taught to read during the earliest years of schooling". Anak-anak harus diajarkan membaca selama tahuntahun awal sekolah, karena kemampuan anak dalam membaca merupakan pintu masuk bagi siswa untuk mengembangkan literasi dan meningkatkan minat baca siswa sejak dini.

Membaca, menulis dan berhitung merupakan pondasi bagi suatu sistem pendidikan dan pembelajaran (Whitten, Labby \& Sullivan, 2016; Hwa, 2018). Pondasi yang dimaksudkan adalah kecakapan siswa dalam hal membaca, menulis dan berhitung merupakan kecakapan dasar yang harus dimiliki oleh siswa untuk mendapatkan pengetahuan baru, jika siswa tidak memiliki kemampuan tersebut akan sulit bagi siswa untuk mendapatkan pengetahuan baru. Berdasarkan pentingnya pembelajaran calistung dan penguatan pendidikan karakter yang telah dijabarkan, maka peneliti menyarankan penguatan pendidikan karakter di sekolah dapat dilakukan dengan tidak mengorbankan anak untuk terlambat belajar calistung, karena kedua hal tersebut sama pentingnya dan dapat dilaksanakan beriringan.

Kebijakan penghapusan calistung di kelas rendah sekolah dasar jika dilaksanakan, pada penerapannya sekolah dapat menyiasatinya program atau pembelajaran calistung dengan menyisipkan pada pembinaan karakter atau dalam permainan edukasi. Pembelajaran membaca, menulis dan berhitung dapat diintegrasikan ke dalam program penguatan pendidikan karakter yang telah di rencanakan, dan juga ke dalam permainan edukasi. Pada awal masa sekolah atau kelas rendah sekolah dasar, Guru lebih banyak mengajak anak untuk bermain sambil belajar. Metode yang dapat digunakan oleh guru yakni permainan edukasi (Katmada, Mavridis \& Tsiatsos, 2014; Cohrssen, Church \& Tayler, 2016), melalui permainan edukasi yang dilakukan oleh siswa, guru dapat menyisipkan pembelajaran calistung kedalamnya.

\section{SIMPULAN DAN SARAN}

\section{Simpulan}

Kebijakan penghapusan pembelajaran calistung pada kelas rendah sekolah dasar di Kota Malang terus menuai pro dan kontra. Berdasarkan hasil analisis data dan interpretasi teoritik yang telah dilakukan disimpulkan berikut ini, (1) Perumusan masalah kebijakan dilakukan peneliti menggunakan metode indepth analysis. Inti dari merumuskan masalah kebijakan adalah didapatinya permasalahan substantif yaitu masalah kecakapan dan kurikulum sekolah, (2) Hasil peramalan kebijakan menunjukkan daya cakap siswa terhadap calistung lambat, dan (3) Rekomendasi kebijakan yaitu pemerintah kota dalam hal ini dinas pendidikan kota Malang seyogyanya segera menyusun panduan kebijakan sebagai pedoman pelaksanaan kebijakan bagi sekolah. Bagi sekolah pada penerapannya dapat menyiasati program atau pembelajaran calistung dengan menyisipkan pada pembinaan karakter atau dalam permainan edukasi.

\section{Saran}

Berdasarkan kesimpulan yang sudah dirumuskan saran bagi, (1) Kepala Dinas Pendidikan Kota Malang adalah seyogyanya segera menyusun panduan kebijakan sebagai pedoman pelaksanaan kebijakan bagi sekolah, (2) Kepala Sekola hendaknya pada penerapan kebijakan penghapusan calistung dapat menyiasati program atau pembelajaran calistung dengan menyisipkan pada pembinaan karakter atau dalampermainan edukasi; (3) Peneliti lain, hendaknya mampu merumuskan alternatif kebijakan yang tepat dalam rangka penguatan pendidikan karakter siswa dengan tidak melupakan pembelajaran calistung. 


\section{DAFTAR RUJUKAN}

Adams, P. 2015. Education Policy: Explaining, Framing, and Forming. Journal of Education Policy, 31 (3), 290307.

Calistung Kelas 1-2 SD Dihapus, Ada yang Khawatir. JPNN.Com (Online), (https://www.jpnn.com/news/ calistung-kelas-1-2-sd-dihapus-ada-yang-khawatir). Diakses 1 Mei 2019.

Cohrssen, C., Church, A., \& Tayler, C. 2016. Play-Based Mathematics Activities as a Resource for Changing Educator Attitudes and Practice. SAGE Open, 6 (2), 1-14.

Creswell, J.W. 2014. Research Design: Qualitative, Quantitative, and Mixed Methods Approaches 4th Edition. London: Sage Publication.

Cullinan, B. E. 2000. Independent Reading and School Achievement. School Library Media Research, 3 (1), 1-24.

Damayanti, S.N. 2017. Analisis Prospektif Kebijakan Pengalihan Kewenangan Pendidikan Menengah dari Pemerintah Kota Surabaya ke Pemerintah Provinsi Jawa Timur Berdasarkan UU No. 23 Tahun 2014 Tentang Pemerintah Daerah. Jurnal Kebijakan dan Manajemen Publik, 5 (3), 1-12.

Dunn, W.N. 2000. Public Policy Analysis, An Introduction. New York: Prentice-Hall, Inc.

Guven, S., Ozturk, A., \& Duman, S.N. 2016. Needs analysis of responsibility curriculum for primary school students. Educational Research and Reviews, 11(19). 1831-1840.

Hwa, S. P. 2018. Pedagogical change in mathematics learning. Educational Technology and Society, 21 (4), 259-276.

Kapan Waktu yang Tepat Bagi Anak Belajar Calistung? Educenter.id (Online), (https://www.educenter.id /belajarcalistung/amp/). Diakses 1 Mei 2019.

Katmada, A., Mavridis, A., \& Tsiatsos, T. 2014. Implementing a Game for Supporting Learning in Mathematics. Electronic Journal of e-Learning, 12 (3), 230-242.

Knoepfel, P. 2007. Public Policy Analysis. UK: The Policy Press University of Bristol.

Lundy, L. 2012. Children's Rights and Educational Policy in Europe: The Implementation of the United Nations Convention on the Rights of The Child. Oxford Review of Education, 38 (4), 393-411.

Sahlberg, P. 2007. Education Policies for Raising Student Learning: The Finnish Approach. Journal of Education Policy, 22 (2), 147-171.

Saniy, M.M.A. 2014. Perbandingan Prestasi Belajar Matematika Siswa SD Negeri Sampangan 02 Semarang yang Mendapat Calistung dan Tidak Mendapat Calistung di Taman Kanak-Kanak. Educational Psychology Journal, 3 (1), 14-18.

Stokey, E. 2009. A Primer For Policy Analysis. USA: W.W Norton \& Company.

Tahun Ajaran Baru, Pemkot Malang Bakal Uji Coba Kurikulum Pendidikan Karakter dan Penghapusan Calistung. Malangtimes.com (Online), (https://www.malangtimes.com/baca/37744/20190403/143400/tahun-ajaranbaru-pemkot-malang-bakal-uji-coba-kurikulum-pendidikan-karakter-dan-penghapusan-calistung). Diakses 1 Mei 2019.

Ulfatin, N. 2015. Metode Penelitian Kualitatif di Bidang Pendidikan: Teori dan Aplikasinya. Malang: Media Nusa Creative.

Whitten, C., Labby, S., \& Sullivan, S. L. 2016. The impact of Pleasure Reading on Academic Success. The Journal of Multidisciplinary Graduate Research, 2 (4), 48-64. 